\title{
Supply, Demand, and Policy Environment for Pulses in Pakistan
}

\author{
MUBARIK ALI and ABEDULLAH
}

\begin{abstract}
This paper fills an information gap regarding factors affecting the supply and demand of pulses in Pakistan. The short- and long-term supply elasticities were estimated using the Nerlovian partial adjustment process, while demand elasticities were estimated by applying the Deaton and Muellbauer Almost Ideal Demand System (AIDS). Generally lack of technological innovation in pulses, except in mungbean, has reduced their production and they are pushed to low intensive areas which are marginal for cereal and cash crop production. Pulses did not benefit from the investment in irrigation infrastructure. Increase in wage rates has further affected the mungbean and lentil production. On the demand side, contrary to normal belief, pulses have high own-price demand and income elasticities. Thus decline in pulses consumption is not caused by their being regarded as inferior goods, rather it can be attributed to disproportionate increase in pulses price, as laxity in pulses research left their production behind demand. The high-yielding, short-duration, and pest-resistant pulses varieties with synchronised maturity can revive their production trend as well as improve the dietary pattern, especially of the poor.
\end{abstract}

Black gram, mungbean, lentil, and mash are the major pulses grown in Pakistan. Pulses production in the country declined from 836 thousand $t$ in 1973 to 614 thousand $t$ in 1994-95 (Table 1). Laxity of policy-makers for food legumes and introduction of high-yielding, input-responsive varieties of cereals during the late 1960s and 1970s not only reduced the pulses yield, but also pushed pulses cultivation to marginal lands. For example, per ha yield of pulses declined from $514 \mathrm{~kg}$ in 1973 to $419 \mathrm{~kg}$ in 1993, while wheat yield increased from $1248 \mathrm{~kg}$ to $1893 \mathrm{~kg}$ during the corresponding period (Table 1). The contribution of the three major mungbeangrowing districts in 1993-94-all relatively marginal for cereals-in the total mungbean area in Pakistan was only 3 percent in 1970. This increased to 70 percent in 1992 (Fig. 1). Thus, lack of modern technologies for pulses made their cultivation unsuitable in intensive farming systems.

Combining the declining trends in pulse production with the population explosion in the country, domestic annual per capita production of the legumes decreased from $9.5 \mathrm{~kg}$ to $3.4 \mathrm{~kg}$ during the period (Table 1). Prices of pulses jumped as compared to other food items such as wheat (Fig. 2). This has serious implications for the supply of protein to the poor population who do not have resources to buy

Mubarik Ali is Agricultural Economist, Asian Vegetable Research and Development Centre, Taiwan. Abedullah is Consultant, Social Sciences, International Rice Research Institute, Manila. 
Table 1

Area (000 ha), Production (000t), Average Yield (kg/ha) and Availability ( kg/capita) of Pulses, and Wheat Yield ( $\mathrm{kg} / \mathrm{ha})$ in Pakistan, 1973-1993

\begin{tabular}{|c|c|c|c|c|c|}
\hline \multirow[b]{2}{*}{ Year } & \multicolumn{4}{|c|}{ Pulses } & \multirow[b]{2}{*}{ Wheat Yield } \\
\hline & Area & Production & Yield & Availability & \\
\hline 1973 & 1626.8 & 836.3 & 514 & 9.20 & 1248 \\
\hline 1974 & 1376.9 & 715.6 & 520 & 7.55 & 1320 \\
\hline 1975 & 1476.5 & 783.7 & 531 & 8.03 & 1422 \\
\hline 1976 & 1533.3 & 843.5 & 550 & 8.38 & 1431 \\
\hline 1977 & 1544.7 & 811.6 & 525 & 7.85 & 1316 \\
\hline 1978 & 1676.6 & 735.8 & 439 & 6.96 & 1488 \\
\hline 1979 & 1550.9 & 512.2 & 330 & 4.86 & 1568 \\
\hline 1980 & 1252.5 & 525.5 & 419 & 4.80 & 1643 \\
\hline 1981 & 1321.1 & 488.2 & 369 & 4.37 & 1565 \\
\hline 1982 & 1335.4 & 693.7 & 520 & 5.85 & 1678 \\
\hline 1983 & 1306.7 & 709.9 & 543 & 5.76 & 1482 \\
\hline 1984 & 1415.3 & 725.5 & 513 & 5.73 & 1612 \\
\hline 1985 & 11451.5 & 796.7 & 549 & 6.08 & 1881 \\
\hline 1986 & 11521.6 & 790.9 & 520 & 5.85 & 1559 \\
\hline 1987 & 1222.3 & 556.1 & 455 & 4.07 & 1734 \\
\hline 1988 & 1394.9 & 641.8 & 460 & 4.50 & 1865 \\
\hline 1989 & 11496.4 & 768.5 & 514 & 5.20 & 1825 \\
\hline 1990 & 11538.2 & 732.1 & 476 & 4.81 & 1841 \\
\hline 1991 & 11420.4 & 706.2 & 497 & 4.50 & 1990 \\
\hline 1992 & 11453.1 & 547.1 & 377 & 3.47 & 1946 \\
\hline 1993 & 11480.9 & 614.0 & 415 & 3.75 & 1893 \\
\hline
\end{tabular}

Source: Pakistan (1975 and 1982) issues.

Per capita availability was estimated by subtracting 31 percent of the production in the case of gram, and 10 percent in the case of other pulses as seed requirement. 


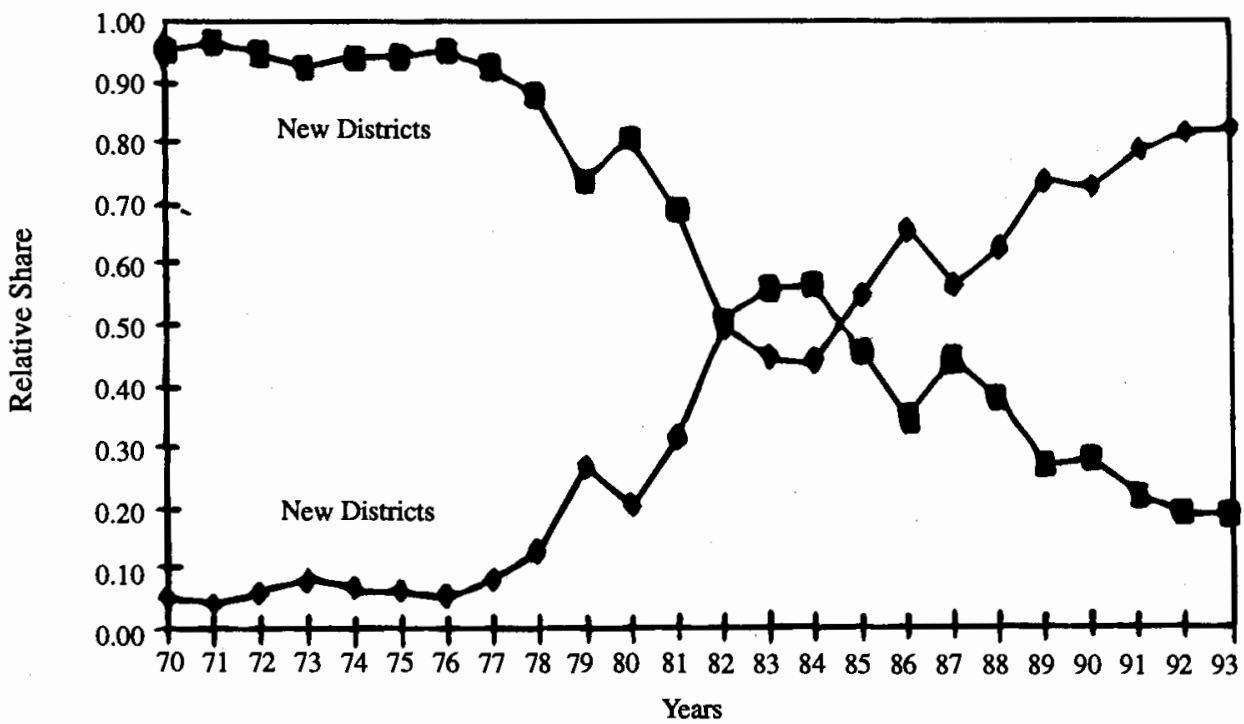

Vorc: New disticis are Layyah, Bhakar, and Mianwali. while old districts are all others.

Fig. 1. Mungbean, Pulses, and Wheat Prices in Pakistan.

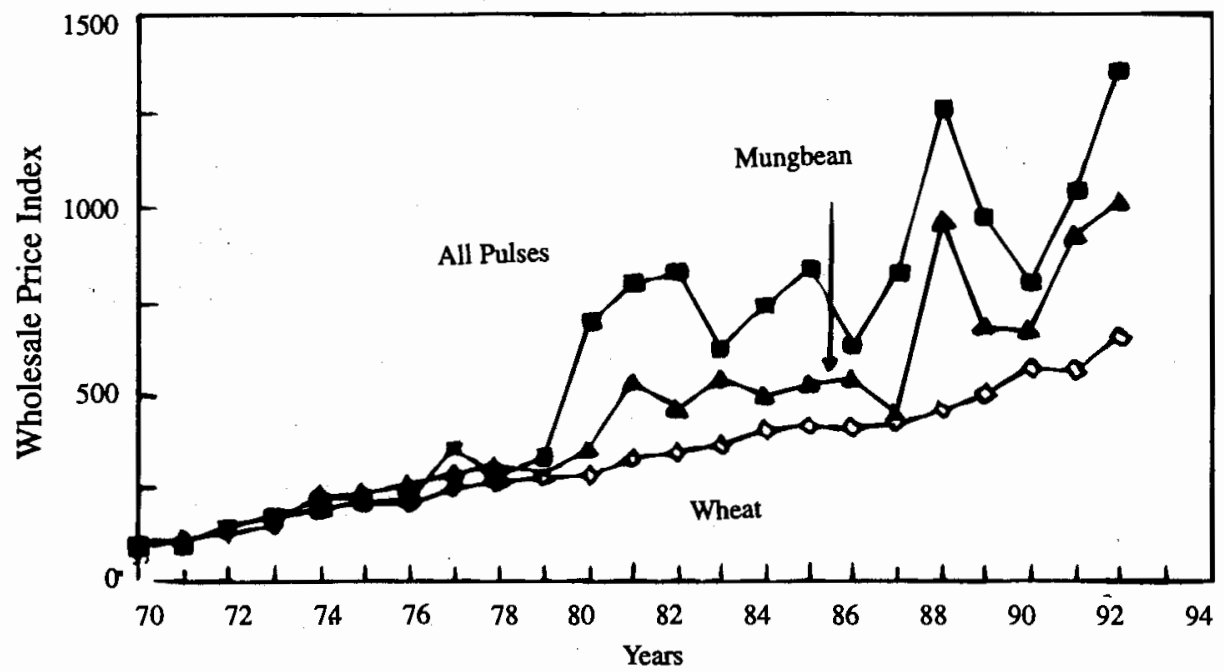

Source: Pakistan (1972), Pakistan (1983). Pakistan (1995a).

Note: The pulses prices are weighted average of wholesale prices of gram (Lahore), lentil (Faisalabad), and mash (Multan). The relative share in total production was used as weights. Mungbean prices are wholesale prices in Karachi markel.

Fig. 2. Relative Changes in the Wholesale Prices of all Pulses, Mungbean, and Wheat in Pakistan, 1970-94. 
expensive livestock-based protein-rich food. In a failed attempt to halt this decline, the government has to spend considerable foreign exchange on the import of pulses, which has progressively increased from nil in 1975 [Pakistan (1978)] to 254 thousand $\mathrm{t}$ in 1993 [Pakistan (1995)]. ${ }^{1}$

Supply and demand of a commodity are determined by the policy environment and consumers' preferences. Very little is known how these factors affect the pulses production and consumption. The main objective of this paper is to fill the information gap related to pulses supply and demand. Understanding these factors will help policy-makers in formulating appropriate policies and research agenda to boost pulses production and encourage their consumption in the country. The next section describes the theoretical framework to estimate the supply and demand functions for pulses, while Section 3 declineates the empirical models. Section 4 explains the data sources and Section 5 discusses the results. The last section summarises the results and suggests the future policy and research implications.

\section{THEORETICAL MODELS}

\section{Supply Response}

In general, the production response of a crop is assumed to be a function of the expected own-price $\left(P^{*}{ }_{i t}\right)$, expected prices of other crops $\left(P_{j t}^{*}\right)$, input prices $\left(W_{t}\right)$, and fixed factors $\left(Z_{t}\right)$ at the time $(t)$ the decision to produce a crop $(i)$ is made. This can be expressed as follows:

$$
Y_{i t}^{*}=f\left(P_{i t,}^{*} P_{j t,}^{*} W_{t}, Z_{t,} \alpha^{*}, \chi^{*}, \gamma^{*}, \tau^{*}\right) \quad \ldots \quad \ldots \quad \ldots
$$

$Y_{i t}^{*}$ is the desired level of production of the $i$-th crop farmers want to produce in response to the expected price regime at time $t ; \alpha^{*}, \chi^{*}, \gamma^{*}, \tau^{*}$ are the long-term production response of the crop with respect to its own-price, the prices of other crops, input prices, and fixed factors, respectively.

Assuming the profit-maximising behaviour of farmers, $\alpha^{*}$ will be positive, and $\gamma^{*}$ will be negative. However, $\chi^{*}$ will be positive if the $i$-th and the $j$-th crops are complementary, negative if they are substitute, and zero if independent. $\tau^{*}$ may be positive or zero depending upon the role of the fixed factors in production.

${ }^{1}$ Similar trends were observed in other countries where the Green Revolution in cereals was pushed hard. For example, in India which is one of the major pulses-producing countries in the world, total pulses area declined from 23.6 million ha in 1960 to 22.4 million ha in 1993, and the share of pulses in total food grain area dropped from 20 percent to 18 percent; total production remained stagnant around 12-13 million t but daily per capita availability declined from 65.5 gram to 37.0 gram in the corresponding period [India (1994)]. The increase in pulses prices was 40 percent higher than in cereal prices just during 1982-93 [India (1995)]. 
Farmers can not fulfil their plan to produce a desired level of output because of difficulties in making necessary arrangements instantly. Therefore, Nerlovian adjustment process is used to replace unobservable values of desired production $\left(Y_{t}^{*}\right)$ with the observable one $\left(Y_{t}\right)$ as follows [Nerlove (1958)]: ${ }^{2}$

$$
\begin{array}{lllllll}
Y_{t} / Y_{t-1}=\left(Y_{t}^{*} / Y_{t-1}\right)^{\beta} & \ldots & \ldots & \ldots & \ldots & \ldots
\end{array}
$$

where $Y_{t-1}$ is the production of the crop in the preceding year, and $\beta$ is the adjustment coefficient. Substituting the values of $Y^{*}$ from Equation (2) into Equation (1), and shifting the denominator to the right-hand side will give:

$$
Y_{i t}=f\left(Y^{1-\beta}{ }_{i(t-1)}, P^{*}{ }_{i t}, P^{*}{ }_{j t}, W_{t}, Z_{t}, \alpha, \chi, \tau\right) \quad \ldots \quad \ldots \quad \ldots
$$

The adjustment coefficient $(\beta)$ can be estimated from the coefficient of the lagged production variable. It should be noted that inclusion of $Y_{(t-1)}$ in the right-hand side of the equation has changed $\alpha^{*}, \chi^{*}, \gamma^{*}, \delta^{*}$ (the long-term response paramters) to $\alpha=\alpha^{*}(1-$ $\beta), \quad \chi=\chi^{*}(1-\beta), \gamma=\gamma^{*}(1-\beta), \tau=\tau^{*}(1-\beta)$ (the short-term response paramters). The former can be estimated by dividing the latter with one minus the adjustment coefficient [Nerlove (1958)].

Still Equation (3) is unobservable because it includes the expected rather than observed output prices. There are many ways to estimate the expected prices [Pindyck and Rubinfeld (1978)]. This study utilises the previous year's (or lagged by one year) prices as the expected prices for this year. Using one year's lag operator on output prices, Equation (3) can be written as:

$$
Y_{i t}=f\left(Y^{1-\beta}{ }_{t-1}, P^{*}{ }_{i(t-1)}, P_{j(t-1,)}^{*} W_{t}, Z_{t}, \alpha, \chi, \gamma, \tau\right) \quad \ldots \quad \ldots \quad \ldots
$$

All the variables in Equation (4) are now observable. Thus it can be estimated using normal estimation procedures.

\section{Demand Function}

The Almost Ideal Demand System (AIDS) due to Deaton and Muellbauer (1980) was applied to estimate the demand function for all food items including pulses. $^{3}$ The specification not only helps to estimate the own-price, but also cross-

${ }^{2}$ The Nerlovian partial adjustment model assumes a rigid rather than a rational price expectation behaviour without incorporating any explicit cost of adjustment. Despite these problems, the assumption in the model keeps the error term free of the autoregressive scheme, and thus can be applied without prior worry about the autocorrelation problem in the lagged model. However, if such a problem is detected by the $d$ statistics, special estimation techniques can be applied. The model is widely used in empirical research because of its ease in application and interpretation of the results [Koutsoyiannis (1977)].

${ }^{3}$ Numerous algebraic specifications of the demand system are available, including the linear expenditure and quadratic expenditure systems [Swamy and Binswanger (1983)], the working and translog models [Christensen, Jorgenson, and Lau (1975)], the Rotterdam and Almost Ideal Demand Systems (AIDS) [Deaton and Muellbauer (1980)]. The last two models are more widely used to characterise the consumers demand behaviour. 
price and income elasticities of demand. The model is specified as follows:

$$
\omega_{i}=\psi_{i}+\sum_{j} \eta_{i j} \ln p_{i j}+\phi_{i} \ln \left(X / P^{*}\right)+v_{i} \quad \text { for all } i \ldots . \quad \ldots
$$

where $i$ represents the $i$-th commodity $(i=1,2, \ldots m), j$ is the $j$-th price in each equation $(j=i=1,2, \ldots m), \omega$ is the expenditure share defined as expenditure on the $i$ th commodity divided by the total expenditure on all food items, $p$ is the commodity price, $X$ is the total expenditure on all food items, $\ln$ is the natural logarithm, and $v$ is the error term. The $\ln P^{*}$ is defined as:

$$
\ln P^{*}=\Phi_{0}+\sum_{i} \eta_{i} \ln p_{i}+0.5 \sum_{i} \sum_{j} \kappa_{i j} \ln p_{i} \operatorname{lnp}_{j} \quad \ldots \quad \ldots \quad \ldots
$$

This leads to non-linearity in parameter of the demand model, and can be estimated by maximum likelihood (ML). However, as Buse (1994) noted, the ML estimation is usually avoided in favour of the computationally attractive linearised model such as the ordinary least square (OLS) or seemingly unrelated regression (SUR). To convert the model in (6) into linear in parameters, Deaton and Muellbauer (1980) suggested to replace $\ln p^{*}$ with the stone's geometric price index as follows.

$$
\ln P^{*}=\sum_{i} \omega_{i} \ln p_{i}
$$

The adding up, homogeneity, and symmetry restrictions can be expressed in terms of the model's coefficient [Moschini and Meilke (1989)]:

$$
\begin{array}{llll}
\sum_{i} \Psi_{i}=1, \sum_{i} \eta_{i j}=0, \sum_{i} \phi_{i}=0 & \text { (adding up) } & \ldots & \ldots \\
\sum_{i} \eta_{i j}=0 & \text { (homogeneity) } & \ldots & \ldots \\
\eta_{i j}=\eta_{j i} & \text { (symmetry) } & \ldots & \ldots
\end{array}
$$

These restrictions can be imposed in the normal way, except the adding up restriction, which is imposed by deleting one of the equations and estimating the parameters of the deleted equation through the residual method.

Under the assumption that the error term $v$ in (5) has multivariate normal distribution, uncorrelated over time, but contemporaneously correlated such as:

$$
\begin{array}{ll}
\mathrm{E}\left(\mathrm{v}_{i t}\right)=0 & \\
\mathrm{E}\left(\mathrm{v}_{i t}, v_{j t}\right)=\Omega_{i j} & \\
\mathrm{E}\left(\mathrm{v}_{i t}, v_{j q}\right)=0 & \text { for } t \neq q,
\end{array}
$$

the parameters in (5) with $\Delta \ln P^{*}$ as in (6) and restrictions in (7-9) can be estimated using the Iterated Seemingly Unrelated Regression (ITSUR) method of the SYSLIN procedure in SAS. The parameters obtained by ITSUR converage to their maximum 
likelihood values if the error term follows a multivariate normal distribution [Judge et al. (1985)] and they are invariant to the choice of the deleted equation.

Following Green and Alston (1990), the price and expenditure elasticities are estimated as follows:

Price elasticities (uncompensated) $=\varepsilon_{i j}=-\delta_{i j}+\left[\left(\eta_{i j}\right)-\omega_{j}(\phi)\right] / \omega_{I}$ for all $i$ and $j$

Price elasticities (compensated) $=\varepsilon_{i j}{ }^{*}=\varepsilon_{i j}+\omega_{j} \varepsilon_{i}$

Expenditure or scale elasticities $=\varepsilon_{i}=1+\phi / \omega_{i} \quad \ldots \quad \ldots$

where $\delta_{i j}$ is the Kronecker data (its value is one for $i=j$ and zero for $i \neq j$ [Green and Alson (1990)] $\varepsilon_{i i}$ (i.e., own price elasticities) are expected to be negative. For normal goods, $\varepsilon_{i}$ is positive, and negative for inferior goods. The $\varepsilon_{i j}$ (i.e., cross-price elasticities) may be positive if the two commodities are substitutes, negative if they are complimentary, and zero if independent. The statistical significance of the elasticities was tested using the $F$-test at the mean values of factor share.

\section{EMPIRICAL MODELS}

The following empirical supply model was estimated separately for the four major pulses, i.e., mungbean, gram, mash, and lentil, which is an elaborated form of Equation (4).

$$
\begin{aligned}
& Y_{i t}=Y_{0}+(1-\beta) Y_{(t-1)}+\alpha P_{m(t-1)}+\chi_{6} P_{g(t-1)}+\chi_{7} P_{h(t-1)}+\chi_{8} \mathrm{P}_{1(t-1)}+\chi_{5} \mathrm{P}_{a(t-1)}+ \\
& \chi_{1} P_{w(t-1)+}+\chi_{2} P_{r(t-1)}+\chi_{3} P_{c(t-1)}+\chi_{4} P_{s(t-1)}+\gamma W_{t}+\tau_{1} I_{t}+\tau_{2} \mathrm{C}+\tau_{3} T+ \\
& \begin{array}{llllll}
\sum_{d=1} d_{d} D_{d}+e_{t} & \ldots & \ldots & \ldots & \ldots & \ldots
\end{array}
\end{aligned}
$$

where $Y_{i t}$ is as defined before; $P_{m}, P_{g}, P_{h}, P_{l}, P_{w}, P_{r}, P_{c}, P_{s}, P_{a}$ are, respectively, mungbean, gram, mash, lentil, wheat, rice, cotton, sugarcane, and maize prices in Rupees per $100 \mathrm{~kg}$; $W$ is wage rate in Rupees per day; $I, C$, and $T$ are the fixed factors in pulses supply. The $C$ is cropping intensity (defined as total cropped area divided by net sown area) indicating the pressure on land to produce food and raw materials; $I$ is the proportion of irrigated area in the total cropped area representing public and private investment on the development of irrigation infrastructure; $T$ is a trend variable to capture the effect of relative technological change in pulses, having the values $0,1,2, \ldots$ for $1970,1971,1972, \ldots \ldots$; $D$ is dummy variable for district having a value of one for the $d$-th district and zero otherwise; ${ }^{4} t$ denotes the $t$-th year; $(t-1)$ is a difference operator indicating the variable is lagged by one year; $e$ is a random error term assumed to be randomly and normally distributed; and $Y_{0}$ is the intercept of the supply equation. The function was estimated in logarithm form by

${ }^{4}$ The district boundaries in the data were maintained as they existed in 1965. So the data for a new district were added in the old district from where the new district was created [Ali (1996)]. We had 19 districts in Punjab. To avoid complete collinearity between districts and intercept, only 18 district dummy variables can be included in the equation. 
taking the natural log of all the dependent and independent variables, except the trend and dummy variables. ${ }^{5}$ The Ordinary Least Squares method was used to estimate Equation (11). Assuming the homogeneity of degree one (i.e., no change in production if the prices of all outputs and inputs are changed proportionately), one price variable can be omitted from the equation, and it can be used to normalise all other prices [Ali (1990)]. We use fertiliser price $\left(P_{f}\right)$ to normalise all the output prices and wage rate.

In the demand analysis, our main interest was to estimate the demand elasticities of pulses. Therefore, other individual food items were aggregated into the following ten food groups: (i) wheat; (ii) gram, (iii) mash, (iv) mungbean, (v) lentil, (vi) milk (fresh and bioled, milk packed, dry and condensed, butter, ghee, yougart, all converted into liquid milk equivalent), (vii) meat (mutton, beef, fish fresh, and chicken), (viii) fruit (citrus fruits, mango, apple, melon, and grapes), (ix) vegetables (tomato, onion, and other vegetables), and (x) other cereals (rice and potato). The Equation (5) was elaborated for all the food groups, expect for "other cereals", which was deleted for estimation purposes, but its parameters were recovered by invoking the adding-up restriction.

\section{DATA}

In the supply-response analysis, district-level data on production and harvest prices of the major pulses, harvest prices of major crops (wheat, rice, cotton, sugarcane, and maize), wage rate, fertiliser prices, proportion of irrigated area, and total cropped area in Punjab ${ }^{6}$ for 1970-93 were used. Agricultural Statistics of Pakistan [Pakistan (1975), (1978), (1980), (1982), (1984), (1987), (1990), (1993) issues] and Punjab Agricultural Statistics [Agricultural Department of Punjab (1977), (1977a), (1978), (1982), (1983), (1991) issues] regularly publish districtlevel area under major crops. The harvest prices of agricultural commodities until 1980 are also published in the latter source. The prices for 1980-93 were obtained from the official files of Crop Reporting Services, Directorate of Agriculture, Lahore. Where district-level prices were missing, these were taken from a neighbouring district. Fertiliser prices at the retail-level were obtained from the Economic Survey of Pakistan [Pakistan (1994)]. District-wise cropped and irrigated areas were taken from the Punjab Agricultural Statistics, and in case missing, these were obtained from the official files of Crop Reporting Services, Directorate of Agriculture, Lahore. Wage rate was obtained from the Wage Census Reports published by the Land Record office in Lahore for 1966, 1973, 1978, and 1988

${ }^{5}$ The log-linear form of supply response was selected because of its ease in estimation and in explaining the coefficient, as estimated coefficients directly give elasticities.

${ }^{6}$ We restrict our analysis for only Punjab province because more than 75 percent of the total pulses in the country are produced in this province [Pakistan (1995)]. Moreover, district-level output prices are available only for Punjab. 
[West Pakistan (1969); Punjab (1978); Punjab (1987); Punjab (1993)]. The wage rate for the in-between years was extrapolated using a constant growth rate between the census years [see Ali (1996) for more details on how these data series were assembled and generated].

To estimate the demand function as specified in Equation (5), one needs prices and expenditure share on various consumption items. Household income and expenditure surveys, known as HIES for short, report consumption and expenditure on different food items by income, province, and rural and urban group. The HIES data for 1986-87, 1987-88, and 1988-89 [Pakistan (undated); Pakistan (1987); (1988a)] were used in this analysis. The latest household survey (changed from Household Income and Expenditure Survey to Integrated Economic Survey) did not publish data on consumption by province and rural and urban group [Pakistan (1993)], and were thus excluded from the analysis. The prices of different food items were estimated by dividing expenditure with the respective consumption quantities.

\section{Pulses Supply}

\section{RESULTS AND DISCUSSION}

The exercise to estimate the supply response aims to understand the role of input and output prices, investment on irrigation infrastructure, technology generation, and population pressure in the production of pulses in Pakistan.

The estimated supply response model explained a 84-93 percent variation in the production of different pulses, as indicated by the value of $\mathrm{R}^{2}$. The $F$-values ranged from 72-177; each is significant at the 1 percent level. The Durbon-Watson statistics is around two, indicating no serious auto-correlation problem. The lag coefficients, as expected, are positive in all cases, and highly significant (Table 2). This implies that farmers failed to achieve their desired production in the same year because of the structural problems.

The short-term own-price supply elasticities of mungbean and lentil are positive and significant at least at the 15 percent level. Gram and mash productions are not responsive to their own respective prices, perhaps because of the subsistence nature of these crops. The respective values of the own-price supply elasticities of mungbean and lentil are 0.223 and 0.138. Singh and Singh (1988) estimated the supply elasticity of mungbean in India (probably in the medium-term) as 0.5 .

Pulses production, especially of mungbean, is affected by other crop prices. The important competing crop for mungbean is mash. A 1 percent increase in price of the former will decrease the production of the latter by 0.4 percent in the short term. This is because both crops are grown in the same season [Ahmad et al. (1993)], and regional distribution of these crops overlapped on a good proportion of the area. Maize, cotton, gram, and lentil are complementary crops to mungbean. In the case of 
Table 2

Supply Response Parameters of Major Pulses in Pakistan, 1970-93



maize, the use of spring mungbean as a catch crop in between maize-wheat rotation can explain this relationship. In the case of cotton, mungbean cultivation after its harvest, when farmers get lucrative cotton prices which induce them for an extra picking and discourage wheat cultivation [Byerlee et al. (1987)], explains this relationship.

The productions of lentil and gram are also complementary with mungbean, probably because both the crops are grown in different seasons (i.e., lentil in September-March, gram in December-May, and mungbean mainly in JulySeptember), and some farmers might be growing them in sequence. So a good harvest from gram and lentil could provide the cash necessary to arrange the inputs for the mungbean crop. Mungbean production seems to be independent of the prices of wheat, rice, and sugarcane.

Lentil competes with cotton and mungbean, mainly because of their overlapping growing season. High mungbean prices discourage lentil, as mungbean can delay lentil cultivation if grown on the same piece of land. (It should be noted that high prices of lentil encourage mungbean production, as enough time is 
available to prepare mungbean field after the harvest of lentil crop). Lentil production is independent of the prices of wheat, rice, sugarcane, maize, gram, and mash.

Gram production competes with wheat and mash, because of their overlapping period. Similarly, mash and sugarcane are competing crops. Gram is complementary with mungbean as explained earlier.

Mungbean and lentil productions are negatively affected by the increasing wage rate, as these crops need high labour input, especially in harvesting their pods, which occurs 3-4 times in case of traditional varieties as these do not mature uniformly. Moreover, the demand for harvesting labour in these pulses may compete with the planting labour of cash crops such as rice and cotton. A 1 percent increase in the wage rate would reduce their production by about 0.3 percent in each case.

The effect of cropping intensity on production is negative in all pulses, except in gram, although insignificant in the cases of mungbean and mash. This implies that pulses are mainly concentrated in areas with low cropping intensities. Although gram is concentrated in more intensive areas, this does not imply that it is a preferred crop in the intensified cropping regions. Actually, it is used as a fall-back crop, i.e., cultivated when the main wheat crop is not successful both in terms of productivity and return. Its association with wheat as an inter-crop also explains this result.

The coefficient for the proportion of irrigated area is insignificant in all cases. This implies that pulses production has not benefitted from the public and private investment on irrigation infrastructure. The trend coefficient is positive and significant only in mungbean, and its production increased at the rate of 1.2 percent during 1970-93 after controlling the effect of relative prices. The production declined in gram, mash, and lentil, although the trend was not statistically significant in the case of mash.

The long-term elasticities are derived from the short-term elasticities of production (Table 3) in case the latter are significant at the 15 percent level. Although

Table 3

Long-term Supply Elasticities of Major Pulses in Pakistan, 1970-93

\begin{tabular}{lcccc}
\hline Independent Variable & Mungbean & Gram & Mash & Lentil \\
\hline$P_{m(t-1)}$ & 1.178 & 0.770 & - & -0.537 \\
$P_{g(t-1)}$ & 1.215 & - & - & 0.237 \\
$P_{h(t-1)}$ & -1.812 & -2.241 & - & - \\
$P_{l(t-1)}$ & 1.055 & - & - & 0.340 \\
$P_{w(t-1)}$ & - & -1.617 & - & - \\
$P_{c(t-1)}$ & 0.197 & 0.057 & - & -0.106 \\
$P_{s(t-1)}$ & - & - & -1.338 & - \\
$P_{a(t-1)}$ & 1.287 & - & - & - \\
$W_{t}$ & -1.449 & - & - & -0.706 \\
$I_{t}$ & - & - & - & 0.675 \\
$C_{t}$ & - & 0.715 & - & -0.355 \\
$T$ & 0.056 & -0.100 & - & -0.070 \\
\hline
\end{tabular}


the short-term elasticities of mungbean supply are small, its long-term elasticities are more than 1.0. The own-price long-term supply elasticity of mungbean is comparable to those of rice and cotton (commercial crops) at 1.9 and 1.3, respectively [Ali (1990)]. The big difference in the short- and long-term elasticities is an indication of the difficulties in adjusting mungbean production in response to its prices in the short-term, as limited area is available for its cultivation and it is mainly concentrated in the mungbean-growing region on the fallow land after wheat, while its expansion in new areas competes with cereals and other cash crops. Mash and wheat productions pose even stronger competition for gram in the long term. The elasticities of mungbean and lentil production with respect to the wage rate are relatively high in the long term.

\section{Pulses Demand}

Pulses are consumed as daal cooked separately or, sometime, with other pulses, meat, and egg. Daal is a base food eaten with chapati prepared from wheat flour. Sometimes they are used in snacks called haleem and pakora, and also in sweets. But the use of pulses as a vegetable, in the form of sprouts, is unknown. Very little is known about consumers' relative preference for pulses in the food basket. To fill this knowledge gap, the own- and cross-price demand and income elasticities are estimated, and the results are discussed in the following section.

Compensated and uncompensated demand elasticities are very similar to each other (Tables 4 and 5), although the latter is slightly higher than the former. Therefore, only uncompensated elasticities are discussed below.

Individual pulses have higher own-price demand elasticity than wheat, a staple food in Pakistan. For example, a 1 percent increase in gram, mash, mungbean, and lentil prices will decrease their consumption by 0.74 percent, 0.73 percent, 0.67 percent, and 0.83 percent, respectively, while the own-price elasticity of wheat is only 0.27 percent. The high own-price demand elasticity of pulses is comparable with other high-quality food items such as milk, meat, and other cereals (mainly rice), where a 1 percent increase would bring a decrease in their consumption by 0.94 percent, 0.76 percent, and 0.61 percent, respectively. However, fruit and vegetables have relatively low own-price elasticities of demand than meat, milk, and pulses, but they have higher elasticities than wheat (Table 4).

The own-price demand elasticities of pulses estimated in this analysis are comparable with those in other countries in the region. For example, Singh and Singh (1988) estimated the elasticity of pulses in India as -1.0 for the low-income group, and -0.2 for the high-income group.

Mungbean is a complementary food with mash, because as mash consumption decreases with the increases in its price, so does the consumption of mungbean. However, it is a substitute for lentil, milk, and fruit, because as the consumption of these items decreases with the increase in their respective prices, the consumption of 


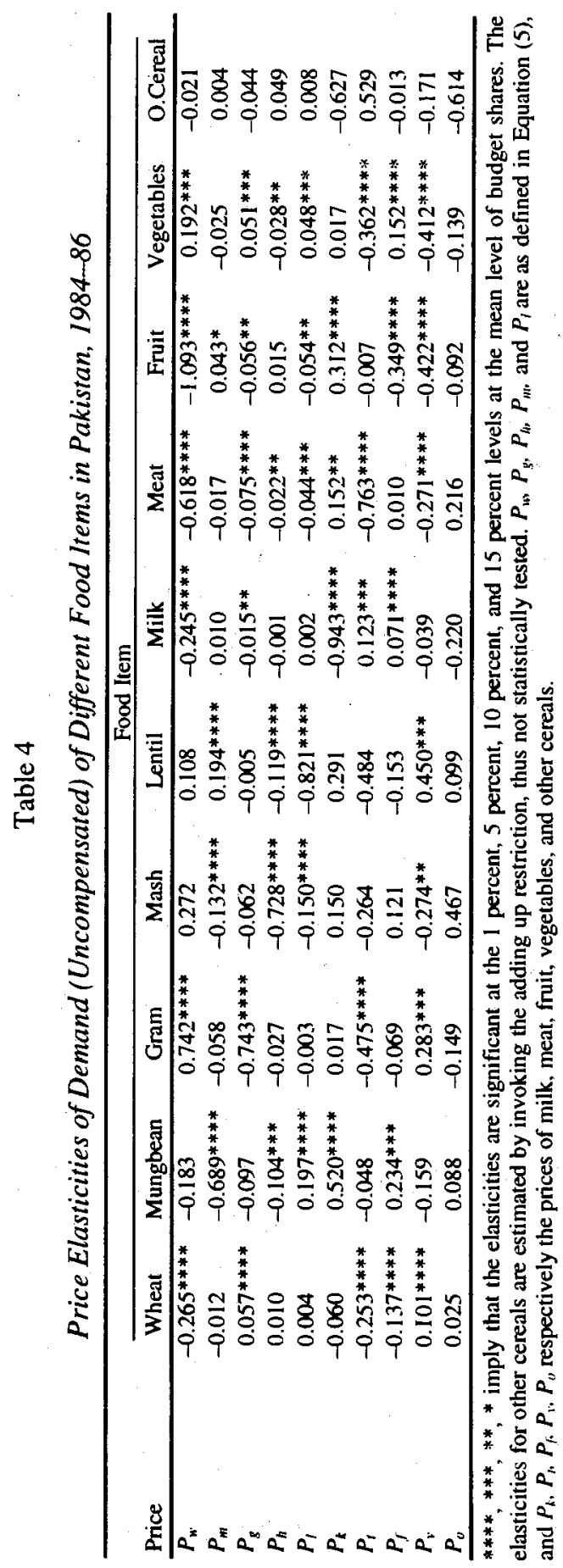


Table 5

Compensated Demand Elasticities

\begin{tabular}{lrrrrrrrrrr}
\hline & \multicolumn{8}{c}{ Food Item } \\
\cline { 2 - 11 } Price & Wheat & Mungbean & Gram & Mash & Lentil & Milk & Meat & Fruit & Vegetables & O.Cereal \\
\hline$P_{w}$ & -0.127 & -0.120 & 0.868 & 0.429 & 0.223 & 0.083 & -0.244 & -0.648 & 0.403 & 0.214 \\
$P_{m}$ & -0.005 & -0.686 & -0.053 & -0.125 & 0.199 & 0.024 & 0.000 & 0.063 & -0.016 & 0.015 \\
$P_{g}$ & 0.068 & -0.093 & -0.733 & -0.050 & 0.004 & 0.011 & -0.046 & -0.021 & 0.068 & -0.026 \\
$P_{h}$ & 0.015 & -0.102 & -0.023 & -0.723 & -0.115 & 0.011 & -0.009 & 0.031 & -0.020 & 0.057 \\
$P_{l}$ & 0.010 & 0.200 & 0.002 & -0.143 & -0.816 & 0.017 & -0.028 & -0.034 & 0.058 & 0.019 \\
$P_{k}$ & 0.090 & 0.588 & 0.153 & 0.320 & 0.415 & -0.588 & 0.557 & 0.793 & 0.246 & -0.373 \\
$P_{t}$ & -0.162 & -0.007 & -0.391 & -0.160 & -0.408 & 0.340 & -0.515 & 0.287 & -0.222 & 0.684 \\
$P_{f}$ & -0.113 & 0.245 & -0.047 & 0.148 & -0.133 & 0.128 & 0.076 & -0.272 & -0.115 & 0.028 \\
$P_{v}$ & 0.154 & -0.135 & 0.331 & -0.214 & 0.494 & 0.087 & -0.128 & -0.251 & -0.332 & -0.081 \\
$P_{o}$ & 0.070 & 0.109 & -0.108 & 0.518 & 0.137 & -0.113 & 0.338 & 0.053 & -0.070 & -0.537 \\
\hline
\end{tabular}

mungbean increases. The mungbean and other pulses are independent (of wheat and other cereals) food items, except gram, which is a substitute for wheat (Table 4). These results partly contradict those reported by Chopra and Swami (1988), who report pulses as strong substitutes for cereals. Lentil is a substitute and mash is complementary with vegetables, and gram is complementary with meat. Mungbean, mash, and lentil consumption are insensitive to the changes in the prices of gram and meat, as cross-price elasticities with respect to these food items are insignificant.

Pulses are believed to be inferior commodities, such that their consumption is expected to decline with an increase in income. Contrary to this belief, our estimate gave positive income elasticities for all individual pulses (Table 6). Mungbean turned out to be a less preferred pulse, as its income elasticity is the lowest. However, the elasticity is non-negative. Therefore, we reject the hypothesis that pulses including mungbean are the inferior good as defined in economic jargon. The income elasticities of other food items are as expected and comparable with other studies [Alderman (1988)].

Table 6

Income Elasticities of Demand of Different Food Items in Pakistan, 1984-86

\begin{tabular}{ll}
\hline Food Item & Elasticity \\
\hline Wheat & $0.530^{* * * *}$ \\
Mungbean & $0.241^{* * * *}$ \\
Gram & $0.483^{* * * *}$ \\
Mash & $0.601^{* * * *}$ \\
Lentil & $0.440^{* * * *}$ \\
Milk & $1.28^{* * * *}$ \\
Meat & $1.433^{* * * *}$ \\
Fruit & $1.705^{* * * *}$ \\
Vegetables & $0.809^{* * * *}$ \\
Other Cereal & $0.900^{* * * *}$ \\
\hline
\end{tabular}




\section{SUMMARY AND CONCLUSIONS}

The neglect of food legumes by policy-makers caused a serious decline in their availability on the one hand, and created a knowledge gap on the other. For example, the supply and demand elasticities, which are so critical in understanding the production and consumption patterns, making plans, and analysing the impact of technological change, are rarely available for all pulses in general, and for individual pulses in particular. The current analysis fills this information gap.

The general perception is that pulses are subsistence crops, and they do not respond to the changes in the policy environment, especially relative prices. This may actually be an effect of the neglect of pulses by policy-makers. For example, the introduction of technological innovations in the art of their cultivation [Ali et al. (1996)] has made them a commercial crop, and farmers have started weighing their profitability with other crops rather than just meeting the family requirements irrespective of the market demand. Their short-term own-price demand elasticity is comparable with wheat, while long-term elasticity matches with other commercial crops, such as rice and cotton, in the country.

Pulses production is mainly concentrated in areas with low cropping intensity. This suggests that their production is normally pushed to low fertile lands, which are marginal to main cereal and cash crop production. The negative effect of cropping intensity on the supply of pulses also reflects farmers' low preference for using pulses in averting the pressure to produce more food and raw materials from land.

Pulses production has not benefitted from the public and private investment in irrigation infrastructure, as unlike cereals, water-responsive pulses varieties are not available. Similarly, the negative trend coefficient, except in mungbean, reflects a paucity of research innovations in pulses in general. The positive trend in mungbean production is mainly due to the belated Green Revolution process begun during the mid 1980s.

Increasing wage rate negatively affects mungbean and lentil production. Therefore, varieties with synchronised maturity which can significantly reduce the harvesting labour demand, as well as mechanical technologies, will help to boost the production of these pulses.

Pulses generally have high demand elasticity, and low but positive income elasticities. This is contrary to what is believed - that pulses are inferior food items, and their consumption declines as income increases. The decline in food legume consumption during the 1970s and 1980s, therefore, can be attributed to disproportional increase in pulses prices combined with high demand elasticity, rather than due to income increase. Actually, income and population increase will continue to put demand pressure on pulses in the future. Unless this pressure is relieved by creating additional supplies, it will simply push pulses prices up, reduce consumption, and thus create more imbalance in diet, especially of the poor people. High-yielding, short-duration, and pest-resistant pulses varieties having synchronised 
maturity and mechanical technologies for their production will greatly benefit consumers and producers, as well as bring long-term sustainability to the production system.

\section{REFERENCES}

Agricultural Department of Punjab (1977) Punjab Agricultural Statistics, 1972-73, 1973-74, and 1974-75. Lahore: United Printers.

Agricultural Department of Punjab (1977a) Punjab Agricultural Statistics, 1975-76. Lahore: United Printers.

Agricultural Department of Punjab (1978) Punjab Agricultural Statistics, 1976-77. Lahore: United Printers.

Agricultural Department of Punjab (1983) Punjab Agricultural Statistics, 1977-80. Vols. I \& II. Lahore: Youth Printers.

Agricultural Department of Punjab (1991) Punjab Agricultural Statistics, 1980-81 to 1989-90. Lahore: Directorate of Agriculture Crop Reporting Services.

Ahmed, B., Z. Hussain, and J. Longmire (1993) Farm Management Handbook, Economics and Policy Analysis Project (Chemonics International Consulting Division), Agricultural Services Sector Project (ASSP) and United States Agency for International Development (USAID), Islamabad.

Alderman, H. (1988) Estimates of Consumer Price Response in Pakistan Using Market Prices as Data. The Pakistan Development Review 17:2 89-107.

Ali, M. (1990) The Price Response of Major Crops in Pakistan: An Application of the Simultaneous Equation Model. The Pakistan Development Review 29:3\&4 305-325.

Ali, M. (1996) Total Factor Productivity Data Set: Definition, Source, and Transformation. AVRDC, Tainan, Taiwan.

Ali, M., H. M. Sabir, B. Ahmed, and I. A. Malik (1997) Green Revolution in Mungbean for Sustainability and Human Nutrition: Understanding the Interface of Technology, Farmers, and Environment in Pakistan. AVRDC Technical Paper (in press).

Barten, A. P. (1969) Maximum Likelihood Estimation of a Complete System of Demand Equation. European Economic Review 1: 7-73.

Buse, A. (1994) Evaluating the Linearised Almost Ideal Demand System. American Journal of Agricultural Economics 76: 781-793.

Byerlee, D., M. R. Akhtar, and P. R. Hobbs (1987) Reconciling Conflicts in Sequential Cropping Patterns Through Plant Breeding: The Example of Cotton and Wheat in Pakistan's Punjab. Agriculture System 24: 291-304.

Chopra, K., and G. Swami (1988) Pulses: An Analysis of Demand and Supply in India 1951-71. New Delhi: Sterling Publishers.

Christensen, L. R., D. W. Jorgenson, and L. J. Lau (1975) Transcedental Logrithmic Utility Functions. American Journal of Economic Review 65: 367-83. 
Deaton, A., and J. Muellbauer (1980) An Almost Ideal Demand System. The American Economic Review 70:3 312-326.

Green, R., and J. M. Alston (1990) Elasticities in AIDS Models. American Journal of Agricultural Economics 72: 442-445.

Judge, G. C., W. E. Griffiths, R. C. Hill, H. Lutkepohl, and T. C. Lee (1985) The Theory and Practice of Econometrics, 2nd Edition. New York: John Wiley \& Sons.

Koutsoyiannis, A. (1977) Theory of Econometrics, 2nd Edition. London: Macmillan.

Moschini, G., and K. D. Meilke (1989) Modelling the Pattern of Structural Change in U. S. Meat Demand. American Journal of Agricultural Economics 71: 253261.

Nerlove, M. (1958) Distributed Lag and Estimation of Long-run Supply and Demand Elasticities: Theoretical Consideration. Journal of Farm Economics 40: 301-310.

Pakistan, Government of (1973) 25 Years of Pakistan in Statistics, 1947-72. Karachi: Central Statistical Office, Economic Affairs Division, Ministry of Finance, Planning and Development.

Pakistan, Government of (1975) Agricultural Statistics of Pakistan 1975. Vol. II. District-wise Area and Production of Important Crops. Islamabad: Ministry of Food, Agriculture and Cooperatives, Under Developed Areas and Land Reforms, Agriculture Wing (Planning Unit).

Pakistan, Government of (1978) Agricultural Statistics of Pakistan 1977. Islamabad: Ministry of Food, Agriculture and Cooperatives, Food and Agriculture Division (Planing Unit).

Pakistan, Government of (1980) Agricultural Statistics of Pakistan 1979. Islamabad: Ministry of Food, Agriculture and Cooperatives, Food and Agriculture Division (Planning Unit).

Pakistan, Government of (1982) Agricultural Statistics of Pakistan 1981. Islamabad: Ministry of Food, Agriculture and Cooperatives, Food and Agriculture Division (Planning Unit).

Pakistan, Government of (1983) 10 Years of Pakistan in Statistics. Karachi: Central Statistical Office, Economic Affair Division, Ministry of Finance, Planning and Development.

Pakistan, Government of (1984) Agricultural Statistics of Pakistan 1983. Islamabad: Ministry of Food, Agriculture and Cooperatives, Food and Agriculture Division (Planning Unit).

Pakistan, Government of (1987) Agricultural Statistics of Pakistan 1986. Vol. II, Districtwise Area and Production of Important Crops. Islamabad: Ministry of Food, Agriculture and Cooperatives, Food and Agriculture Division (Planning Unit).

Pakistan, Government of (1988) Agricultural Statistics of Pakistan 1987-88. Islamabad: Ministry of Food, Agriculture and Cooperatives, Food and Agriculture Division (Planning Unit). 
Pakistan, Government of (1988a) Household Income and Expenditure Survey, 198586. Karachi: Federal Bureau of Statistics, Statistics Division.

Pakistan, Government of (1989) Household Income and Expenditure Survey, 198687. Karachi: Federal Bureau of Statistics, Statistics Division.

Pakistan, Government of (1990) Crop Area and Production (By District), 1986-87 to 1988-89. Islamabad: Ministry of Food, Agriculture and Cooperatives, Food and Agriculture Division, Economic Wing.

Pakistan, Government of (1993) Crop Area and Production (By District), 1989-90 to 1991-92. Islamabad: Ministry of Food, Agriculture and Cooperatives, Food and Agriculture Division, Economic Wing.

Pakistan, Government of (1993a) Household Integrated Economic Survey, 1990-91. Karachi: Federal Bureau of Statistics, Statistics Division.

Pakistan, Government of (1994) Economic Survey 1993-94. Karachi: Finance Division, Economic Advisor's Wing.

Pakistan, Government of (1995) Agricultural Statistics of Pakistan 1993-94. Islamabad: Ministry of Food, Agriculture and Livestock, Food and Agriculture Division, Economic Wing.

Pakistan, Government of (1995a) Pakistan Statistical Year Book 1994. Federal Bureau of Statistics, Economic and Statistics Division.

Pakistan, Government of (undated) Household Income and Expenditure Survey, 1986-87. Karachi: Federal Bureau of Statistics, Statistics Division.

Pindyck, R. S., and D. Rubinfeld (1978) Econometric Models and Economic Forecasts, Second Edition. New York: McGraw Hill Inc.

Punjab, Government of (1978) Report on the Eleventh Regular Wage Survey of the Punjab Taken in June 1973. Lahore: Government Printing Press.

Punjab, Government of (1987) Report on the Twelfth Regular Wage Survey of the Punjab taken in June 1978. Lahore: Government Printing Press.

Punjab, Government of (1993) Report on the Fourteenth Regular Wage Survey of the Punjab Taken in December 1988. Lahore: Government Printing Press.

Singh, R. K., and R. I. Singh (1988) Recent Trends in Marketing Mungbean in Uttar Pradesh, India. In Mungbean: Proceedings of the Second International Symposium. AVRDC, Tainan, Taiwan, 463-469.

Swamy, G., and H. P. Binswanger (1983) Flexible Consumer Demand Systems and Linear Estimation: Food in India. American Journal of Agricultural Economics 675-684.

West Pakistan, Government of (1969) Report on the Tenth Regular Wage Survey of the West Pakistan (Northern Zone) Taken in December 1966. Peshawar: West Pakistan Government Press. 